\title{
Improvement of Prosperity Prediction in Czech Manufacturing Industries
}

\author{
Michal Kubenka \\ University of Pardubice \\ Studentska 95, 53210 Pardubice, Czech Republic \\ E-mail.michal.kubenka@upce.cz \\ cross $^{\text {ref }}$ http://dx.doi.org/10.5755/j01.ee.29.5.18231
}

\begin{abstract}
There are many ways to determine financial health of a company. Classic tools of financial analysis emphasize data in financial statements. When trying to reach an overall classification of a company, e.g. from the point of view of an investor, indicators of profitability, liquidity, leverage and activity might generate contradictory clues regarding financial health of the company. Such analysis does not only generate ambiguous results, but is also lengthy. Therefore, the IN05 financial model was created for particular specifics of the Czech Republic economic environment to predict prosperity of companies. It measures the prosperity on the base of economic value added (EVA). More than ten years have passed since the launch of the INO5 index. The aim of this study is to quantify contemporary prediction strength of the INO5 index on a sample of almost 500 companies. Moreover, an effort was made to enhance the accuracy of the model for particular branches of manufacturing industries. It was found that contemporary explanatory power of the index IN05 is $48.58 \%$ when applying the original evaluation scale, and $70.79 \%$ when assessing $68.62 \%$ of the sample except the gray zone. The accuracy of the model was enhanced by the author in all categories, i.e. a higher accuracy (correct prediction probability) without considering the gray zone and higher accuracy (conditioned correct prediction probability) using the gray zones in all branches of manufacturing industries. Robustness of these results was verified on another sample of 195 companies.
\end{abstract}

Keywords: Prediction Model; Financial Health; IN05 Index; Economic Value Added; Return on Equity; Manufacturing Industry.

\section{Introduction}

A plethora of bankruptcy and prosperity prediction models are used worldwide in many modifications. Banks, investors, and business partners use them to assess financial performance of firms and to check their financial health.

According to Svobodova (2013) the increased need to assess financial health of firms is justified by the rising number of insolvency proceedings in the Czech Republic.

Prosperity models are used to assess a current financial situation of a firm using one aggregate indicator. These models combine selected ratios and are based on theoretical assumptions and generally recommended values of these indicators, and, in the vast majority, do not use empirical evidence. Bankruptcy models were created in order to predict the probability of financial distress, thus these models were created on samples of selected firms. Bankrupt-prosperity financial health models combine financial health of firms with their ability to meet their financial obligations. However, despite a long history of these models, there are still used groups of simple ratios for economic and financial stability analysis (e.g. International Monetary Fund; Cernohorska \& Linhartova, 2013).

Prediction models render a certain percentage of failure, which increases over time because of changes happening in the market environment. Therefore, it is necessary to constantly upgrade current models and also create new ones. A model created in 1970 would not work nowadays with the same success rate as it did then.

Kubenka (2014, p. 364) states that the accuracy of existing models may be decreased for several reasons:
- the author created the model on a small sample of heterogeneous firms;

- the author failed to consider the differences and specificities of the branches in which the model should be applied;

- both market conditions and legislation change with the passage of time, while some models are several decades old.

Model accuracy can also be decreased by using nonidentical accounting systems, e.g. applying US GAAP to create models, while utilizing IFRS to apply the same models, causes their lower accuracy. Honkova (2015) and Fosbre (2009) deal with differences in accounting systems (US GAAP vs. IFRS vs. CAS).

After the transformation to the market economy in the 1990's, bankruptcy models started to originate in the Czech Republic to predict company bankruptcies. These models should take the market specificity of the country into account. The IN95 model (Neumaierova \& Neumaier, 2002) was the first bankruptcy model to appear. In 1999 the same authors launched the so-called ownership model named IN99. It predicts prosperity based on a positive economic value added (EVA). In 2001 they created the IN01 model that connects the properties of both previous models, i.e. it predicts bankruptcy as well as prosperity. As early as 2005 it was updated to a version called the IN05 model (Neumaierova, 2005).

The reported prediction strength of the IN05 model was related to a group of Czech firms in the manufacturing industries. It is, however, notable that manufacturing industries, according to CZ-NACE (Classification of Economic Activities of Czech Statistical Office), comprise 21 branches. 
The IN05 was created based on data of all branches included in manufacturing industries from 2003/2004. That is why the author of this article focused also on the factor of a particular industrial branch (manufacturing industry being too wide a term, involving inhomogeneous subjects of activity) and the factor of time (model obsolescence depending on changes of the market environment).

The IN01 was upgraded to IN05 four years after its inception. 4 years later the original model lost its precision. What is the accuracy of the IN05 10 years after its inception? That is why the basic aim is to quantify contemporary prediction strength of the IN05. Moreover, an effort is being made to enhance the accuracy of the model for particular branches of manufacturing industries.

\section{Literature Analysis}

The history of bankruptcy models dates back to the 19th century. One of the pioneers in the field, Dun \& Bradstreet, Inc., was founded in 1841 and has been active in the field ever since (Dun \& Bradstreet, 2015). However, modern specialized studies concerning financial health appeared as late as in the 1930's. One of the most prominent authors was William H. Beaver, who discovered in 1968 that if we use a correct selection of ratios with a suitable coefficient, we are able to predict bankruptcy probability of certain companies several years ahead. In 1968, following Beaver's research from 1966 (Beaver, 1966), Edward I. Altman came up with Z-score formula for predicting bankruptcy using the MDA method. The formula is quite popular and has been updated several times. A number of variants of the formula exists to choose from today.

MDA (multiple discriminant analysis) has been used to predict financial health of companies since 1960's. Its merit is choosing linear combinations of independent variables which best describe the financial state of the company. Altman (1968) was not the only scholar applying MDA principles, there were other researchers (e.g. Green, 1978; Gibson, 1982; Chen \& Shimerda, 1981). MDA analysis was later replaced (e.g. by a logit analysis, applied by Ohlson, 1980, or a probit analysis, which Zmijewski (1984) focused on in 1984). Of these two, the logit analysis is more popular today, especially because the probit analysis requires more extensive calculations (Vochozka, 2011).

The principle of the logit analysis is examining whether the analysed phenomenon, modelled using a random variable, occurs or not. It takes the value of 0 (the phenomenon did not occur) or the value of 1 (the phenomenon occurred) (Cramer, 2003; Aldrich \& Nelson, 1984).

One of the most recent and currently also most frequently used methods is the method of artificial neural networks. It was discovered in 1990 and its principle is analysis of a large number of variables based on a mathematical model. This procedure excludes unimportant variables. It is useful for credit evaluation, analysis of financial transactions to determine fraudulent behaviour and other criminal activities. Neural networks are more accurate than previous methods, but only by several per cent (Kim \& Park, 2012; Chih-fondg \& Chihli, 2014). Neural networks were applied, among others, by Wilson \& Sharda (1994), Zhang (1999), Amendola et al. (2011).
Despite the new methods, MDA is still used to create new models (e.g. by Slavicek, 2015; Durica 2016).

The most widely used bankruptcy models are Altman's Z score formulas, especially Z score model of 1968 (Altman, 1968), ZETA score of 1977 (Altman et al., 1977), and $Z^{\prime}$ score of 1999 (Altman, 2000). Other models include Taffler's index of 1977 (Taffler, 1984) and Beerman's discrimination function of 1976 (Beerman, 1976). The new bankruptcy model created in the Czech Republic is Index of Karas and Reznakova (Karas \& Reznakova, 2014) from 2014, where the indicated accuracy of placing a firm within the health zone is $97.89 \%$, while the indicated accuracy of placing a firm within the distress zone is $69.91 \%$. In 2014, another bankruptcy model was created by Homolka et al., for which the author indicates the prediction accuracy of $90.96 \%$ (Homolka et al., 2014). The latest bankruptcy model to emerge (Karas \& Reznakova, 2017) is focused on construction industry with the accuracy of $92.31 \%$ in bankruptcy prediction and $58.74 \%$ in prosperity prediction. Until then, the Z"'score model (see Altman \& Sabato, 2008) was used for the construction industry (e.g. Kubenka \& Kralova, 2013; Manasova, 2008) with the accuracy of 72.50 $\%$.

The most popular prosperity models in Europe are Tamari's model of 1966 (Tamari, 1966), Grünwald's prosperity index of 1995, Kralicek's Quick test of 1993, and Prosperity Index, which is used in Central Europe (above all in Germany, Austria and Switzerland).

Kubenka and Slavíček (2014) claim that although prosperity and bankruptcy models were created differently, their construction is similar, which means a combination of ratios and assigned weights of importance. Financial diagnostic and prediction models vary predominantly in their targeting.

The only bankruptcy-prosperity models are IN01 and IN05. This third type of financial model is able to evaluate bankruptcy while also prosperity. IN05 was created by the Neumaier couple (Neumaierova \& Neumaier, 2002) with prediction of EVA at $77 \%$ success rate (accuracy verified by the authors in 2005) and its upgraded successor IN05 of 2005 (Neumaierova, 2005) with accuracy of EVA prediction at $83 \%$. There is a lot of models for earnings prediction (e.g. Hou, Van Dijk \& Zhang, 2012; Sheng \& Thevenot, 2012; Duspiva \& Novotný, 2012; Banker \& Chen, 2006) but only IN05 predicts EVA.

All above mentioned financial prediction models are based on historical and present accounting data of firms, and the models are able to predict the future of the firm based on current trends with a relatively high probability. They are popular in the financial world and widely used for their speed and their ease of use.

Many authors stressed that taking non-financial factors into consideration can significantly increase the effectiveness of risk-management systems and dicision-making processes (Korableva \& Kalimullina, 2016). Some authors even focused unconventional non-financial factors (e.g. Hajek, Olej \& Myskova, 2014) indicated eleven categories of annual reports' sentiment which can utilized as the inputs of the prediction models. However, the frequency of use in practice decreases with the increasing complexity of the method (Striteska, 2012). 


\section{Methodology}

\section{IN05 Index and EVA Construction}

The IN05 index as an upgrade of the IN01, differs from its predecessor by having the gray zone interval changed, namely from the interval $\langle 0.75 ; 1.77\rangle$ to $\langle 0.9 ; 1.6\rangle$. The gray zone indicates the scope of results that the model is unable to evaluate and classify tested company as prosperous or bankrupt company. Also, the weight of the indicator ROA (i.e. Return on Assets) was increased. According to Neumaierova (2005) the index has the following form:

$$
\mathrm{IN} 05=0.13 \mathrm{X}_{1}+0.04 \mathrm{X}_{2}+3.97 \mathrm{X}_{3}+0.21 \mathrm{X}_{4}+0.09 \mathrm{X}_{5}
$$

where $\mathrm{X}_{1}$ - total assets / liabilities, $\mathrm{X}_{2}$ - earnings before interest and taxes / interest paid, $X_{3}$ - earnings before interest and taxes / total assets, $\mathrm{X}_{4}$ - revenues / total assets, $\mathrm{X}_{5}$ - current assets / current liabilities.

To evaluate a company, a scale consisting of several intervals is set: the interval "health zone" if $\operatorname{IN} 05 \in(1.6 ; \infty)$ with prediction of positive EVA, the interval IN $05 \in\langle 0.9 ; 1.6\rangle$

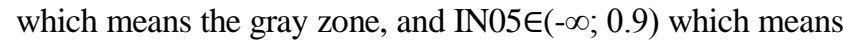
distress zone (negative EVA).

There are more ways to calculate EVA. One of them is, according to Hřebíček (2012) and Machek \& Špička (2014), the following:

$$
\mathrm{EVA}=\left(\mathrm{ROE}-\mathrm{r}_{\mathrm{e}}\right) \times \mathrm{E}
$$

where ROE = EAT / Equity (book value), $r_{e}$ - cost of equity, E - equity, EAT - earnings after taxes.

The calculation according to Neumaier \& Neumaierova (2010) is used in statistics of Ministry of Industry and Trade of the Czech Republic and has this form (based on book values):

$$
r_{e}=\frac{W A C C * \frac{P S}{A}-(1-t) * \frac{I}{B L+O} *\left(\frac{P S}{A}-\frac{E}{A}\right)}{\frac{E}{A}}
$$

where $r_{e}$ - implicit costs of shareholders' capital, PS - paid sources (bank loads, obligations, shareholders' capital), WACC weighted average costs of capital, A - total assets, $\mathrm{t}$ - tax rate, I - cost interests, BL - bank loans, O - obligations, E - equity

The calculation is based on several simplifying assumptions:

- the real or estimated interest rate (loans, bonds) given by the borrowed capital.

- the market value of the borrowed capital equals to the accounting value of the borrowed capital.

- the WACC value is independent of the capital structure, if the indebtedness changes, the total costs of equity are only redistributed among owners and creditors.

- the operational economic result equals to the EBIT value.

The WACC value was calculated according to the methodology of Ministry of Industry and Trade (2016) based on book values:

$$
\mathrm{WACC}=\mathrm{r}_{\mathrm{f}}+\mathrm{r}_{\text {company }}+\mathrm{r}_{\text {finstab }}+\mathrm{r}_{\text {LA }}
$$

where $\mathrm{r}_{\mathrm{f}}$ - rate of the risk-free assets, $\mathrm{r}_{\text {company }}$ - extra charge for the volume of business risk, $r_{\text {finstr }}$ - extra charge for the risk resulting from capital structure, $\mathrm{r}_{\text {finstab }}$ - extra charge for the risk should the company not be able to pay back its liabilities, r LA $_{\text {- is }}$ the risk extra charge for the size of company.

\section{Methodology of Determining Prediction Strength of IN05 for EVA Prediction}

From the formula (2) is apparent the EVA is positive if $\left(\mathrm{ROE}-\mathrm{r}_{\mathrm{e}}\right)>0$. This is deemed as a sufficient condition. The research used economic data of firms for 2014 and 2015. For determining the IN05 prediction accuracy:

a) correct prediction of a positive value of the EVA indicator in situations when EVA predicted for 2014 is positive (it means IN05 $\geq 1.6$ ) and the real value of EVA for 2015 is also positive,

b) incorrect prediction of a positive value of the EVA indicator in situations when EVA predicted for 2014 is positive, but the real value of EVA for 2015 is negative,

c) correct prediction of a negative value of the EVA indicator in situations when EVA predicted for 2014 is negative (it means IN05 $<0.9$ without considering the gray zone) and the real value for 2015 is also negative,

d) incorrect prediction of a negative value of the EVA indicator in situations when EVA predicted for 2014 is negative, but the real value of EVA for 2015 is positive.

Resulting accuracy of the IN05 model for prediction of prosperity (+/-EVA) is then determined as a percentage in the following manner:

$$
\text { Total Accuracy }=\frac{a+c}{a+b+c+d} \times 100
$$

\section{Data Structure and Modification}

The research focused on firms whose core business is manufacturing industry. The three selected branches are: CZNACE 17\&18: Manufacture of paper and paper products, and Printing industry (in 2015 making $2.7 \%$ of total manufacturing industry sales), CZ-NACE 22: Rubber and Plastics Industries (6.7 \%), CZ-NACE 29\&30: Vehicle manufacturing (leading $24.7 \%$ of total manufacturing industry sales). The financial statements of the firms for the years 2014 and 2015 (balance sheet and profit and loss statement) were exported from MagnusWeb application of the Bisnode database. Sample has been selected on the random basis. None of the firms in the researched sample for years 2014 and 2015 showed signs of bankruptcy in the form of insolvency or negative equity.

Table 1

Original Data Structure

\begin{tabular}{|c|c|c|c|}
\hline Symbol & Branch & \multicolumn{2}{|c|}{ Number of firms } \\
\hline A. & Paper and Printing & 146 & $27.04 \%$ \\
\hline B. & Rubber and Plastics & 196 & $36.29 \%$ \\
\hline C. & Vehicles Manufacturing & 198 & $36.67 \%$ \\
\hline A.+B.+C. & Total & 540 & $100 \%$ \\
\hline
\end{tabular}

Source: performed by author

\section{Data Analysis and Data Modification}

The IN05 model is based on CAS (Czech Accounting Standards) accounting data. Only an insignificant number of companies (less than one hundred) is traded on the stock market in the Czech Republic. Thus that is why the return on equity is based on the book value as is the original sample of variables used for creating of IN05. The sample data used is based on the CAS system (non consolidated financial statements) as is the original sample for creating the IN05. 
System CAS is based on Act No. 563/1991 Coll. and Decree 500/2002 Coll.

A sample of 540 companies was analysed from several viewpoints to exclude extreme variables which would negatively influence results of the whole measurement. These extreme values might have been caused by a mistake of evidence or administration, or non-standard development within an acquisition or merger.

Therefore the calculated values of ROE (Return on Equity = Earnings after Taxes / Equity) and obtained values of IN05 underwent the test for outliers.

Table 2 lists the characteristics of resulting values of IN05 before applying Grubbs' test and after the modification using elimination of outliers. Grubbs' outlier test (Grubbs, 1969) calculates the maximum of the absolute differences between the $x_{i}$ values and the mean of the sample. These all divided by the standard deviation (SD). If the resulting test statistic $\mathrm{z}>\mathrm{Z}$ (critical value), the corresponding value can be regarded to be an outlier.

$$
Z=\frac{\max _{i=1 . . n}\left|x_{i-} \bar{x}\right|}{S D}
$$

Characteristics of IN05 ${ }_{2014}$ Values

\begin{tabular}{|l|c|c|}
\hline \multicolumn{1}{|c|}{ Characteristics } & Original sample & GT modification* \\
\hline Mean & 0.9373 & 0.9149 \\
\hline SD & 1.7988 & 0.9343 \\
\hline Number of values & 540 & 494 \\
\hline Significance level & 0.05 (two-sided) & $\mathrm{x}$ \\
\hline Critic. value of Z & 3.8834 & $\mathrm{x}$ \\
\hline IN05max & $\mathrm{x}$ & 4.39 \\
\hline IN05min & $\mathrm{x}$ & -4.52 \\
\hline
\end{tabular}

*after elimination of outliers in IN05 and $\mathrm{ROE}_{2015}$ determined by Grubbs' test (GT) Source: performed by author

Overall 46 subjects were eliminated from the sample using the Grubbs' test for outliers in IN05 and ROE 2014 , and the resulting sample decreased to 494 companies.

As a result, the fundamental characteristics of the sample were changed - see GT modification in table 2 and table 3 .

Table 3

Characteristics of ROE $_{2015}$ Values

\begin{tabular}{|l|c|c|}
\hline \multicolumn{1}{|c|}{ Characteristics } & Original sample & GT modification* \\
\hline Mean & 12.4132 & $13.1431 \%$ \\
\hline SD & 56.0527 & $28.30 \%$ \\
\hline No. of values & 540 & 494 \\
\hline Significance level & $0.05(2$-sided $)$ & $\mathrm{X}$ \\
\hline Critic. value of $\mathrm{Z}$ & 3.8834 & $\mathrm{X}$ \\
\hline ROEmax & $\mathrm{X}$ & $217.18 \%$ \\
\hline ROEmin & $\mathrm{X}$ & $-150.40 \%$ \\
\hline
\end{tabular}

*after elimination of outliers in IN05 a ROE 2015 determined by Grubbs' test (GT). Source: performed by author

\section{Frequency Distribution and Data Correlation}

Determining approximate number of intervals using the formula (Sunaga, 2009):

$$
k=\sqrt{n}
$$

i.e. 22 when $n=494$. The width of the interval was set at IN05 and ROE 2015 in the following way:

$$
h_{k}=\frac{x_{\max }-x_{\min }}{k}
$$

For the sake of clarity the intervals in the figure 1 were enlarged to $h_{k}=0.5$ and thus the number of intervals was decreased to $k=15$. As is clear in Figure 1, and also in Table 4,159 of all values obtained by the IN05 index is within the interval $\langle 0.9 ; 1.6\rangle$, i.e. $32 \%$. Therefore, the original setting of borders disables classification of a significant part of the analyzed sample.

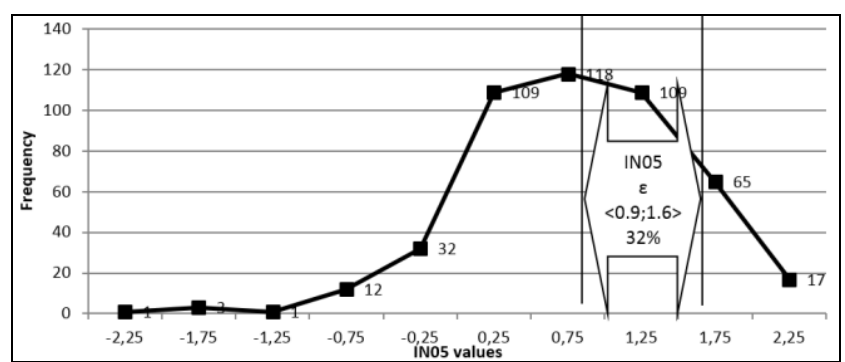

Figure 1. Frequencies of IN05 2014 Values

Note: $2 \%$ of sample not displayed.

This leads to the necessity to find a new evaluation scale, which would emphasize economic development of the industries in the past 10 years (the authors of the model used data from 2003 and 2004, and an update was carried out with financial data from 2014 and 2015).

Table 4

Borders, Frequencies and Percentages of IN05 2014 Values

\begin{tabular}{|c|c|c|c|}
\hline Interval of IN05 & Mid-range & Frequencies (absol.) & Frequencies (rel.) \\
\hline-1.00 & -0.75 & 12 & $2.43 \%$ \\
\hline-0.50 & -0.25 & 32 & $6.48 \%$ \\
\hline 0.00 & 0.25 & 109 & $22.06 \%$ \\
\hline 0.50 & 0.75 & 118 & $23.89 \%$ \\
\hline 1.00 & 1.25 & 109 & $22.06 \%$ \\
\hline 1.50 & 1.75 & 65 & $13.16 \%$ \\
\hline 2.00 & 2.25 & 17 & $3.44 \%$ \\
\hline 2.50 & 2.75 & 14 & $2.83 \%$ \\
\hline 3.00 & 3.25 & 3 & $0.61 \%$ \\
\hline 3.50 & 3.75 & 8 & $1.62 \%$ \\
\hline 4.00 & Total: & $\mathbf{4 8 7}$ & $\mathbf{9 9 \%}$ \\
\hline
\end{tabular}

Note to table 4: Intervals of IN05 with frequencies under $0.5 \%$ not displayed. It represents one percent of the total sample.

Data analysis showed the IN05 2014 median in value 0.9 , mean 0.91 , variance 0.87 , standard deviation 0.93 , maximum of 4.39 , minimum -4.52 .

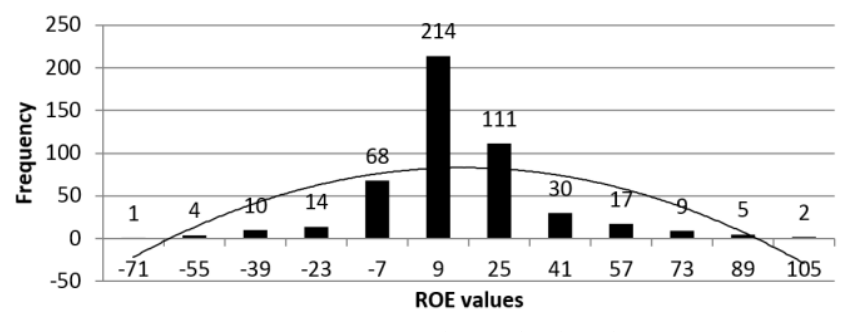

Note: $2 \%$ of sample not displayed.

Figure 2. Frequencies of $\mathrm{ROE}_{2015}$ Values with Polynomial Trendline Source: performed by author 
Data analysis showed the $\mathrm{ROE}_{2015}$ median in value $11.12 \%$, mean $13.14 \%$, variance 799.39 , standard deviation 28.27, maximum of $217.18 \%$, minimum ROE of $-150.40 \%$ (near $20 \%$ of companies with negative ROE).

Table 5

\section{ROE $_{2015}$ Frequencies}

\begin{tabular}{|c|c|c|c|}
\hline Interval & Mid-range & Frequencies (absol.) & Frequencies (rel.) \\
\hline$-63 ;-47$ & -55.00 & 4 & $0.81 \%$ \\
\hline$-47 ;-31$ & -39.00 & 10 & $2.02 \%$ \\
\hline$-31 ;-15$ & -23.00 & 14 & $2.83 \%$ \\
\hline$-15 ; 1$ & -7.00 & 68 & $13.77 \%$ \\
\hline $1 ; 17$ & 9.00 & 214 & $43.32 \%$ \\
\hline $17 ; 33$ & 25.00 & 111 & $22.47 \%$ \\
\hline $33 ; 49$ & 41.00 & 30 & $6.07 \%$ \\
\hline $49 ; 65$ & 57.00 & 17 & $3.44 \%$ \\
\hline $65 ; 81$ & 73.00 & 9 & $1.82 \%$ \\
\hline $81 ; 97$ & 89.00 & 5 & $1.01 \%$ \\
\hline & Total: & $\mathbf{4 8 2}$ & $\mathbf{9 7 . 5 7 \%}$ \\
\hline
\end{tabular}

Note: Intervals of IN05 with frequencies under $0.5 \%$ not displayed. It represents $2.43 \%$ companies of the total sample. Source: performed by author

To visualize relationships between $\mathrm{ROE}_{2014}$ (EVA determinant in 2014), IN05 (it predicts future surplus ROE over $r_{e}$ ) and $\mathrm{ROE}_{2015}$ (it determines the accuracy of the prediction) standardization of data was performed. Comparison is presented in fig. 3 .

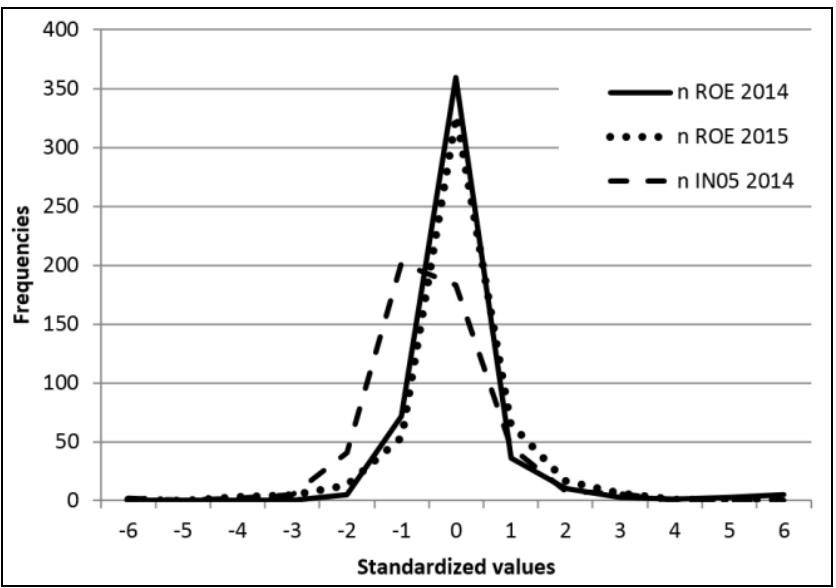

Figure 3. Frequencies of Standardized Values IN05 $2014, \mathrm{ROE}_{2014}$, $\mathrm{ROE}_{2015}$

Source: performed by author
The power of the correct prediction of the positive EVA (specified in chapter Methodology of determining.. item a)) and the correct prediction of a negative EVA (specified in chapter Methodology of determining.. item c)) was tested using Pearson correlation coefficient. At the original setting of evaluation scale $\langle 0.9 ; 1.6\rangle$ the values of 0.24 and 0.42 were obtained respectively. When testing shifting borders the correlation of the value of 0.43 increased at the interval setting $<0.8 ; 0.8>$ without using the gray zone. The border 0.8 was in the middle of tested borders. The results of this analysis are listed in Table 6 and Table 7 below.

\section{Results and Discussion}

The IN05 index was applied on a sample of companies and probability $(\mathrm{P})$ of a correct EVA prediction (both positive and negative) was found to be at $48.58 \%$ using original borders. However, the authors of the model presented its accuracy at the time of its origin on the basis of the conditioned probability (CP) excluding the gray zone. The obtained value of $\mathrm{CP}$ is $70.79 \%$ at the classification capability (CC) of $68.62 \%$ of the sample (i.e. the model is not capable of classifying $31.38 \%$ of the sample of companies, i.e. 31.38 $\%$ of the sample is included in so called "gray zone", it means zone of indecision).

Table 6

Probability of a Correct EVA Prediction Depending on Evaluation Scale

\begin{tabular}{|c|c|c|c|c|c|c|c|c|c|}
\hline & \multicolumn{9}{|c|}{ Evaluation scale } \\
\hline & 0.4 & 0.5 & 0.6 & 0.7 & \begin{tabular}{|l|}
0.8 \\
\end{tabular} & \begin{tabular}{|c|}
0.9 \\
\end{tabular} & 1 & 1.1 & 1.2 \\
\hline 0.4 & 65.38 & 63.56 & 61.54 & 60.12 & 58.1 & 55.67 & 52.23 & 49.19 & 44.94 \\
\hline 0.5 & & 69.23 & 67.21 & 65.79 & 63.77 & 61.34 & 57.89 & 54.86 & 50.61 \\
\hline 0.6 & & & $\mathbf{7 0 . 8 5}$ & 69.43 & 67.41 & 64.98 & 61.54 & 58.50 & 54.25 \\
\hline 0.7 & & & & 70.85 & 68.83 & 66.40 & 62.96 & 59.92 & 55.67 \\
\hline 0.8 & & & & & 71.46 & 69.03 & 65.59 & 62.55 & 58.30 \\
\hline 0.9 & & & & & & 70.85 & 67.41 & 64.37 & 60.12 \\
\hline 1.0 & & & & & & & 70.45 & 67.41 & 63.16 \\
\hline 1.1 & & & & & & & & 69.03 & 64.78 \\
\hline 1.2 & & & & & & & & & 65.79 \\
\hline
\end{tabular}

Now maximum explanatory power (classifying $100 \%$ of the sample of companies) was achieved when setting one borderline of 0.8 . With the border of 0.8 (i.e. evaluation scale $<0.8 ; 0.8>$ ) the IN05 model reaches the highest accuracy of $71.46 \%$.

Conditioned Probability of a Correct EVA Prediction Depending on Evaluation Scale

\begin{tabular}{|c|c|c|c|c|c|c|c|c|c|c|}
\hline & \multicolumn{9}{|c|}{ Evaluation scale } \\
\hline & & 0.4 & 0.5 & 0.6 & 0.7 & 0.8 & 0.9 & 1 & 1.1 & 1.2 \\
\hline \multirow{9}{*}{ 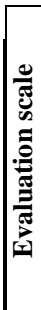 } & 0.4 & $65.38 / 100$ & $68.71 / 93$ & $70.86 / 87$ & $71.57 / 84$ & $73.21 / 79$ & $74.12 / 75$ & $76.11 / 69$ & $76.90 / 64$ & $76.55 / 59$ \\
\hline & 0.5 & & $69.23 / 100$ & $71.24 / 94$ & $71.90 / 92$ & $73.43 / 87$ & $74.26 / 83$ & $76.06 / 76$ & $76.77 / 71$ & $76.45 / 66$ \\
\hline & 0.6 & & & $70.85 / 100$ & $71.46 / 97$ & $72.87 / 93$ & $73.62 / 88$ & $75.25 / 82$ & $75.85 / 77$ & $75.49 / 72$ \\
\hline & 0.7 & & & & $70.85 / 100$ & $72.19 / 95$ & $72.89 / 91$ & $74.40 / 85$ & $74.94 / 80$ & $74.53 / 75$ \\
\hline & 0.8 & & & & & $71.46 / 100$ & $72.09 / 96$ & $73.47 / 89$ & $73.92 / 85$ & $73.47 / 79$ \\
\hline & 0.9 & & & & & & $70.85 / 100$ & $72.08 / 94$ & $72.44 / 89$ & $71.91 / 84$ \\
\hline & 1.0 & & & & & & & $70.45 / 100$ & $70.70 / 95$ & $70.11 / 90$ \\
\hline & 1.1 & & & & & & & & $69.03 / 100$ & $68.38 / 95$ \\
\hline & 1.2 & & & & & & & & & $65.79 / 100$ \\
\hline
\end{tabular}


As can be concluded from Table 6, a higher probability (P) of a correct EVA prediction can be also reached (against the original boundaries) when setting one border at the value of $0.6(\mathrm{P}=70.85 \%), 0.7(\mathrm{P}=70.85 \%), 0.9(\mathrm{P}=70.85 \%)$ and $1.0(\mathrm{P}=70.45 \%)$.

Table 7 lists various combinations of conditioned probability (CP) and classification capability (CC) depending on border modification. When setting a condition $\mathrm{CC} \geq 70 \%$, the most suitable scale seems to be $\langle 0.5 ; 1.1\rangle$. Then, the success rate of prediction of $\mathrm{CP}$ is $76.77 \%$ with capability (CC) of the model to evaluate $71 \%$ companies. Also the combinations listed below yield good results:

$\langle 0.5 ; 1.0\rangle$ with $\mathrm{CP}=76.06 \% / \mathrm{CC}=76 \%$

$<0.6 ; 1.0>$ with $\mathrm{CP}=75.25 / \mathrm{CC}=82 \%$

$<0.6 ; 1.1>$ with $\mathrm{CP}=75.85 / \mathrm{CC}=77 \%$

$<0.6 ; 1.2>$ with $\mathrm{CP}=75.49 / \mathrm{CC}=72 \%$

Results of the application stated in Table 7 show a different accuracy when compared with values given by original evaluation scale $\langle 0.9 ; 1.6\rangle$. The accuracy based on data from the year $2014 / 2015$ showed the probability of the right prediction of $48.58 \%$ and conditioned probability of $70.79 \%$ (at a $68.62 \%$ of CC). Modified evaluation scale yields better results (see Table 6 and Table 7). The confidence interval will determine if this improvement is statistically significant. The confidence interval can be, according to (Pacakova; 2003) or likewise (Kubanova; 2008) determined as follows.

$P\left(p-z_{1-\frac{\alpha}{2}} * \sqrt{\frac{p(1-p)}{n}}<\pi<p+z_{1-\frac{\alpha}{2}} * \sqrt{\frac{p(1-p)}{n}}\right)=1-\alpha$

where $\mathrm{p}$ - the accuracy of IN05 with new evaluation scale, n - the size of the base, $\alpha$ - determined at the level of $5 \%$

\section{NACE 17\&18: Manufacture of Paper and Paper Products and Printing Industry}

IN05 model classified the sample of 137 firms (without outliers) into the distress category in $49.63 \%$ of cases, the gray zone, where the model cannot decide, comprised 28.48 $\%$ and the prosperity zone had $21.89 \%$. If we focus on the ability of correct prediction of financial health, then the prediction strength of IN05 is as follows:

Table 8

IN05 Ability to Predict EVA in NACE $17 \& 18$

\begin{tabular}{|c|c|c|c|}
\hline \multicolumn{2}{|c|}{ EVA prediction success rate* } & \multicolumn{2}{c|}{ No. of firms } \\
\hline a) & correct prediction + EVA** & 21 & $21.43 \%$ \\
\hline b) & incorrect prediction + EVA & 9 & $9.18 \%$ \\
\hline c) & correct prediction - EVA*** & 53 & $54.08 \%$ \\
\hline d) & incorrect prediction - EVA & 15 & $15.31 \%$ \\
\hline \multicolumn{2}{|c|}{ Total: } & $\mathbf{9 8}$ & $\mathbf{1 0 0 \%}$ \\
\hline
\end{tabular}

*not including the gray zone (39 out of 137 firms were classified as belonging to the gray zone or the "zone of indecision).**+EVA means positive EVA, ***-EVA means negative EVA Source: performed by author

The resulting accuracy of the model (with original borders $)$ is then $75.51 \%((21+53) /(21+9+53+15))$. However, if we included the firms in the gray zone (39 firms), the accuracy would drop to $54.01 \%$.
To increase accuracy of the model for the NACE $17 \& 18$ branches, shifting of the evaluation boundaries was tested. It was found that when shifting the gray zone to IN05 $<0.5 ; 1.1>$ the accuracy of the model according to the methodology (5) changed to $77.23 \%(\mathrm{CP})$, while the gray zone was $26 \%$ of the total sample (CC $74 \%$ ). If we use the border 0.8 (scale without gray zone $\langle 0.8 ; 0.8>$ ) the accuracy $(\mathrm{P})$ is $72.99 \%$ (with CC $100 \%$ ).

\section{CZ-NACE 22: Rubber and Plastics Industries}

The classification of the sample of 179 firms (without outliers) by the IN05 model returned results similar to the CZ-NACE $17 \& 18$ branches. The distress category comprises $51.40 \%$, the gray zone has $28.49 \%$ and $20.11 \%$ firms indicates prosperity. If we focus, again, on the ability of correct prediction of financial health only, then according to (5) the prediction strength of IN05 is in table 9.

Table 9

IN05 Ability to Predict EVA in CZ-NACE 22

\begin{tabular}{|c|l|c|c|}
\hline \multicolumn{2}{|c|}{ EVA prediction success rate* } & \multicolumn{2}{c|}{ No. of firms } \\
\hline a) & correct prediction + EVA & 28 & $21.88 \%$ \\
\hline b) & incorrect prediction + EVA & 8 & $6.25 \%$ \\
\hline c) & correct prediction - EVA & 58 & $45.31 \%$ \\
\hline d) & incorrect prediction - EVA & 34 & $26.56 \%$ \\
\hline \multicolumn{2}{c|}{ Total: } & $\mathbf{1 2 8}$ & $\mathbf{1 0 0} \%$ \\
\hline
\end{tabular}

* not including the gray zone (51 out of 179 firms were classified as belonging to the gray zone or the "zone of indecision) Source: performed by author

The resulting accuracy of the model is $67.19 \%$ excluding the gray zone. When the gray zone is included, the accuracy falls to $48.04 \%((28+58) / 179)$.

When shifting of the evaluation boundaries was tested, the gray zone interval $\langle 0.50 ; 1.10\rangle$ changed the model accuracy, increasing it to $74.80 \%(\mathrm{CP})$ with $\mathrm{CC} 71 \%$. The probability $\mathrm{P}$ (the border 0.8 without gray zone) is $68.72 \%$.

\section{CZ-NACE 29\&30: Vehicle Manufacturing}

The sample of 178 firms was classified with similar results as the other branches. $47.19 \%$ fell into the distress category, $36.52 \%$ stayed in the gray zone, and $16.29 \%$ indicated prosperity. The model's ability to predict EVA is as follows.

Table 10

\section{IN05 Ability to Predict EVA in NACE 29\&30}

\begin{tabular}{|c|c|c|c|}
\hline \multicolumn{2}{|c|}{ EVA prediction success rate* } & \multicolumn{2}{c|}{ No. of firms } \\
\hline a) & correct prediction + EVA & 25 & $22.12 \%$ \\
\hline b) & incorrect prediction + EVA & 4 & $3.54 \%$ \\
\hline c) & correct prediction - EVA & 55 & $48.67 \%$ \\
\hline d) & incorrect prediction - EVA & 29 & $25.66 \%$ \\
\hline \multicolumn{2}{c|}{ Total: } & $\mathbf{1 1 3}$ & $\mathbf{1 0 0} \%$ \\
\hline
\end{tabular}

*not including the gray zone ( 65 out of 178 firms were classified as belonging to the gray zone or the "zone of indecision) Source: performed by author 
The resulting accuracy is $70.80 \%$, again excluding the gray zone with CC $63 \%$. After including the gray zone, the accuracy plummets to $44.94 \%$.

After shifting the gray zone interval to $\langle 0.50 ; 1.10\rangle$ the model accuracy would increase to $78.40 \%$ (CP) with CC 70 $\%$. The accuracy without considering the gray zone $(\mathrm{P})$ is $73.03 \%$.

The confidence interval was calculated to verify whether this interval change has a statistically significance. This proves that shifting the evaluation scale $\langle 0.8 ; 0.8\rangle$ and $(0.50 ; 1.10>$ increases the IN05 model accuracy with a statistical significance except branch A for $\mathrm{CP}<0,5 ; 1.1\rangle$. There was original accuracy $75.51 \%$ with borders $<0.9$; $1.6>$ and the new one for $\mathrm{CP}<0.5 ; 1.1>$ is $77.23 \%$ with confidence interval $\langle 70.21 ; 84.25\rangle$. However, more importantly is the $\mathrm{P}$ accuracy from author point of view. $\mathrm{P}$ accuracy in branch A improved from $54.01 \%$ to $72.99 \%$, ie. positive change almost $19 \%$.

Table 11

Original and Modified IN05 Ability to Predict EVA

\begin{tabular}{|c|c|c|c|}
\hline \multicolumn{4}{|c|}{ Original evaluation scale } \\
\hline Branch* & $P\langle 0.9 ; 1.6\rangle$ & $\mathrm{CP}\langle 0.9 ; 1.6\rangle$ & $\mathrm{CC}$ \\
\hline $\mathrm{A}+\mathrm{B}+\mathrm{C}$ & 48.58 & 70.79 & 67 \\
\hline A & 54.01 & 75.51 & 72 \\
\hline B & 48.04 & 67.19 & 72 \\
\hline $\mathrm{C}$ & 44.94 & 70.80 & 63 \\
\hline \multicolumn{4}{|c|}{ Modified evaluation scale } \\
\hline Branch* & $\mathbf{P}(\mathbf{0 . 8 )}$ & CP $<0.5 ; 1.1>$ & $\mathrm{CC}$ \\
\hline $\mathrm{A}+\mathrm{B}+\mathrm{C}$ & 71.46 & 76.77 & 71 \\
\hline A & 72.99 & 77.23 & 74 \\
\hline B & 68.72 & 74.80 & 71 \\
\hline $\mathrm{C}$ & 73.03 & 78.40 & 70 \\
\hline \multicolumn{4}{|c|}{ Confidence intervals } \\
\hline Branch* & $\pi$ of $P(0.8)$ & \multicolumn{2}{|c|}{$\pi$ of $\mathrm{CP}<0.5 ; 1.1>$} \\
\hline $\mathrm{A}+\mathrm{B}+\mathrm{C}$ & $\langle 67.48 ; 75.44\rangle$ & \multicolumn{2}{|c|}{$\langle 73.05 ; 80.49\rangle$} \\
\hline A & $\langle 65.55 ; 80.43\rangle$ & \multicolumn{2}{|c|}{$\langle 70.21 ; 84.25\rangle$} \\
\hline B & $\langle 61.93 ; 75.51\rangle$ & \multicolumn{2}{|c|}{$\langle 68.44 ; 81.16\rangle$} \\
\hline $\mathrm{C}$ & $\langle 66.51 ; 79.55\rangle$ & \multicolumn{2}{|c|}{$\langle 72.35 ; 84.45\rangle$} \\
\hline
\end{tabular}

*Note: Branch A Paper and Printing Industry, branch B Rubber and Plastics Industry, branch $\mathrm{C}$ Vehicles Manufacturing Industry. P - probability, CP conditioned probability, CC - classification capability, $\pi$ - confidence interval

Source: performed by author

The research aims also to prove or disprove whether the model accuracy for various industries differ. Relation between model accuracy and threshold level is shown in figure 4.

The figure shows different accuracy in branch A: Paper and Printing Industry, branch B: Rubber and Plastics Industry and branch C: Vehicles Manufacturing Industry. Branch A: Paper and Printing Industry achieves the highest accuracy $74.45 \%$ with threshold 0.9 . Branch B: Rubber and Plastics Industry achieves the highest accuracy $68.72 \%$ with threshold 0.8. Branch C: Vehicles Manufacturing Industry achieves the highest accuracy $74.72 \%$ with threshold 0.6 .

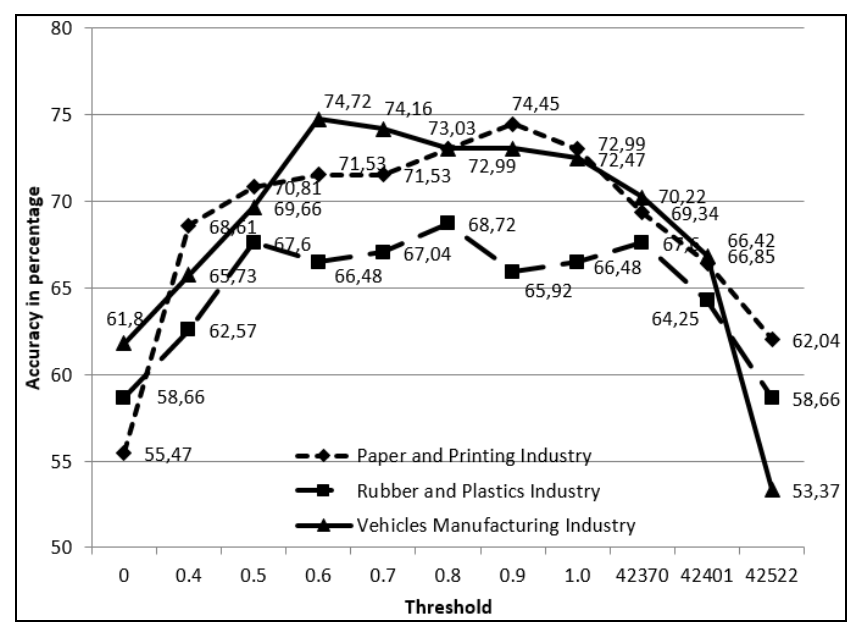

Figure 4. Model Accuracy vs. Threshold vs. Manufacturing Branches

Source: performed by author

To confirm these differences with statistical significance were determined intervals of confidence. It was found that branch B confidence interval is $\langle 59.40 ; 73.40\rangle$ for threshold 0.6. The highest accuracy of branch $\mathrm{C}$ is $74.72 \%$ just for threshold 0.6. This clearly confirms different model accuracy for different branches. Also was found that branch B confidence interval is $\langle 58.98 ; 72.86\rangle$ for threshold 0.9 where is highest accuracy of branch A (it is $74.72 \%$ ). Accuracy of A branch is outside the confidence interval of B. This also clearly confirms different model accuracy for different branches with statistical significance.

We can assume that in other branches may be discovered differences also.

Verification sample confirms robustness of results.

The size of the verification sample was 195 enterprises (random selection from the manufacturing industry).

Table 12

Verification of Modified IN05 Ability to Predict EVA

\begin{tabular}{|c|c|c|c|}
\hline \multicolumn{4}{|c|}{ Original evaluation scale } \\
\hline Branch$^{*}$ & P $<\mathbf{0 . 9} ; \mathbf{1 . 6}>$ & CP $<\mathbf{0 . 9} ; \mathbf{1 . 6}>$ & CC \\
\hline $\mathrm{A}+\mathrm{B}+\mathrm{C}$ & 52.31 & 70.34 & 74.36 \\
\hline \multicolumn{4}{|c|}{ Modified evaluation scale (tested sample) } \\
\hline $\mathrm{A}+\mathrm{B}+\mathrm{C}$ & 71.46 & 76.77 & 71 \\
\hline \multicolumn{4}{|c|}{ Modified evaluation scale (verification sample) } \\
\hline Branch $^{*}$ & P (0.8) & CP $<\mathbf{0 . 5} ; \mathbf{1 . 1}>$ & CC \\
\hline $\mathrm{A}+\mathrm{B}+\mathrm{C}$ & 70.26 & 75.89 & 72.31 \\
\hline
\end{tabular}

Source: performed by author

The IN05 model was unable to evaluate $27.69 \%$ of the verification sample $(25.64 \%$ of the test sample) at the boundary $\langle 0.5 ; 1.1\rangle$ and the accuracy was $75.89 \%(76.77 \%$ of the test sample). The predictive success rate was $70.26 \%$ ( $71.46 \%$ of the test sample) with boundery 0.8 . 


\section{Conclusions}

On the basis of testing a sample of 494 firms, the ability of the IN05 model to predict economic value added has proved to deteriorate significantly over the past 9 years. A considerable weakness of the model showed to be a high probability of classifying a firm within the gray zone, where the model is unable to decide between the distress zone (EVA) and the prosperity zone (+ EVA). The gray zone exceeded $28 \%$ in all three analyzed branches of manufacturing industries (CZ-NACE 17\&18 $28 \%$; CZNACE $2228 \%$; CZ-NACE 29\&30 even $37 \%$ ).

The research also found that the model's ability to predict a positive or a negative value of EVA differs depending on the industrial branch of the firm (branch A $75.51 \%$, branch B $67.19 \%$, branch C $70.80 \%$ ).

The analysis of changes of the IN05 model accuracy depending on shifting the evaluation interval boundaries to $<0.8 ; 0.8>$ and $<0.5 ; 1.1>$ brought an increase of the model's accuracy in all explored branches of manufacturing industries. There was an improvement of $18.98 \%(\mathrm{P})$ with statistical significance and $1.72 \%(\mathrm{CP})$ without statistical significance in branch A (Paper \& Printing Industry).

Nonetheless, in all other industry branches an improvement has occurred with a statistical significance in probability $(\mathrm{P})$ and also in conditioned probability $(\mathrm{CP})$. In branch B (Rubber \& Plastics Industry) an improvement of $20.68 \%(\mathrm{P})$ and $7.61 \%(\mathrm{P})$ has occurred. In branch C (Vehicle Manufacturing Industry) the improvement was $29.09 \%(\mathrm{P})$ and $7.6 \%(\mathrm{CP})$. In the total sample the improvement was $22.88 \%$ in probability and $5.98 \%$ in conditioned probability with $71 \%$ classification capability.

A significant contribution of changing gray zone boundaries from $\langle 0.9 ; 1.6\rangle$ to $\langle 0.8 ; 0.8\rangle$ and $\langle 0.5 ; 1.1\rangle$ has been demonstrated.
The difference in accuracy among branches of Czech manufacturing industries was also tested. A statistically significant difference in accuracy has proved between vehicles manufacturing industry (branch C) vs. Rubber \& Plastics Industry (branch B) with threshold 0.6 (point of maximal accuracy of branch $\mathrm{C}$ ).

The different accuracy between Paper and Printing Industry (branch A) vs. Rubber \& Plastics Industry (branch B) was also statistically confirmed with threshold 0.9 (point of maximal accuracy of branch A).

New accuracy is $72.99 \%$ for branch A, $68.72 \%$ for branch B, $73.03 \%$ for branch $\mathrm{C}$ expressed in probability. New accuracy is $77.23 \%$ for branch A, $74.80 \%$ for branch $\mathrm{B}, 78.40 \%$ for branch $\mathrm{C}$ expressed in conditioned probability.

It should be noted that this model is different from other prosperity models. The correctness of prediction depends on a country's economy and individual risk premiums. It is different for each company in each country. It was created in the specific conditions of the Czech Republic and specifics of selected branches of manufacturing industry which is why it was tested in the Czech Republic.

It would certainly be interesting to have results of application from other countries. However, the author assumes a low accuracy not only with regard to the specifics of the Czech accounting. It can be assumed that a modified model would be required for other countries.

It can also be assumed that better results might be achieved in the future only through respecting other specifications of analyzed firms, and implementing these specifications into financial prediction models as early as in the creation phase or during subsequent weight adjustment of individual components or shifting evaluation boundaries, as was done in this case.

\section{References}

Aldrich, J. H., \& Nelson, F. D. (1984). Linear Probability, Logit, and Probit Models. Beverly Hills: Sage Publications. https://doi.org/10.4135/9781412984744

Altman, E. (1968). Financial Ratios, Discriminant Analysis and the Prediction of Corporate Bankruptcy. The Journal of Finance, 23(4), 589-609. https://doi.org/10.1111/j.1540-6261.1968.tb00843.x

Altman, E. (2000). Predicting Financial Distress of Companies: Revisiting the Z-score and ZETA Models [working paper], New York University. Available from internet: http://pages.stern.nyu.edu/ ealtman/Pred FnclDistr.pdf

Altman, E., Haldeman, E. R., \& Narayanan, P. (1977). Zeta Analysis a New Model to Identify Bankruptcy Risk of Corporations. Journal of Banking \& Finance, 1(1), 29-54. https://doi.org/10.1016/0378-4266(77)90017-6

Altman, E. I., \& Sabato, G. (2008). Modelling Credit Risk for SMEs: Evidence from the U.S. Market. A Journal of Accounting, Finance and Business Studies, 43(3), 332-357.

Amendola, A., Bisogno, M., Restaino, M., \& Sensini, L. (2011). Forecasting Corporate Bankruptcy: Empirical Evidence on Italian Data. EuroMed Journal of Business, 6(3), 294-312. https://doi.org/10.1108/14502191111170132

Banker, R., \& Chen, L. (2006). Predicting Earnings Using a Model Based on Cost Variability and Cost Stickiness. The Accounting Review, 81(2), 285-307. https://doi.org/10.2308/accr.2006.81.2.285

Beaver, W. H. (1966). Financial Ratios as Prediction of Failure. Journal of Accounting Research, 4, 150-161. https://doi.org/10.2307/2490171

Beerman, K. (1976). Possible Ways to Predict Capital Losses With Annual Financial Statements. Dusseldorf: University of Dusseldorf.

Bhunia, A., \& Sarkar (Bagchi), R. (2011). A study of financial distress based on MDA. Journal of Management Research, 3(2), 111. https://doi.org/10.5296/jmr.v3i2.549

Chen, K. H., \& Shimerda, T. A. (1981). An Empirical Analysis of Useful Financial Ratios. Financial Management, 10(1), 51-60. https://doi.org/10.2307/3665113

Chih-Fondg, T., \& Chihli, H. (2014). Modeling Credit Scoring Using Neural Network Ensembles. Kybernetes, 43(7), 1114-1123. https://doi.org/10.1108/K-01-2014-0016 
Cramer J. S. (2003). Logit Models from Economics and other Fields. Cambridge: Cambridge University Press. https://doi.org/10.1017/CBO9780511615412

Cernohorska, L., \& Linhartova, V. (2013) The Impact of Corruption on Soundness of Banking Sector. Proceedings of Finance and the Performance of Firms in Science, Education, and Practice, 199-208.

Durica, M., \& Adamko, P. (2016). Verification of MDA bankruptcy prediction models for enterprises in Slovak Republic. Proceedings of International Days of Statistics and Economics, 400-407.

Duspiva, P., \& Novotny, J. (2012). Utilization of Quantitative Methods in the Decision Making Process of a Manager. Scientific Papers, 17(2), 63-69.

Fosbre, A., Kraft, E., \& Fosbre, P. (2009). The Globalization of Accounting Standards: IFRS vs. US GAAP. Global Journal of Business Research, 3(1), 61-71. Available from internet: http://ssrn.com/abstract=1555184

Gibson, C. (1982). Financial Ratios in Annual Reports. The CPA Journal, 52(9), 18-29.

Green, D. (1978). To Predict Failure. Management Accounting, 7, 39-45.

Grubbs, F. (1969). Procedures for Detecting Outlying Observations in Samples. Technometrics, 11(1), 1-21. https://doi.org/10.1080/00401706.1969.10490657

Hajek, P., Olej, V., \& Myskova, R. (2014). Forecasting Corporate Financial Performance Using Sentiment in Annual Reports for Stakeholders' Decision-making. Technological and Economic Development of Economy, 20(4), 721-738. https://doi.org/10.3846/20294913.2014.979456

Homolka, L., Dolezal, J., \& Novak, P. (2014). Longitudinal Design as an Extension to Standard Banking Approaches to Companies' Financial Performance Assessment and Prediction. Proceedings of European Financial Systems, $236-244$.

Honkova, I. (2015). International Financial Reporting Standards Applied in the Czech Republic. E\&M Ekonomics and Management, 18(3), 94-90. https://doi.org/10.15240/tul/001/2015-3-008

Hou, K., Van Dijk, M., \& Zhang, Y. (2012). The Implied Cost of Capital: A New Approach. Journal of Accounting and Economics, 53(3), 504-526. https://doi.org/10.1016/j.jacceco.2011.12.001

Hrebicek, J., Hodinka, M., Stencl, M., Popelka, O., \& Trenz, O. (2012). Sustainability Indicators Evaluation and Reporting: Case Study for Building and Construction Sector. Proceedings of Conference on Energy \& Environment, 305-312.

International Monetary Fund. Financial Soundness Indicators and the IMF. November 2015. Retrieved Januar 9, 2016, available from internet: https://www.imf.org/external/np/sta/fsi/eng/fsi.htm

Karas, M., \& Reznakova, M. (2014). Possibilities for the Application of a Bankrupcy Prediction Model for Measuring Credit Risk of a Company. Proceedings of Hradec Economic Days, 435-442.

Karas, M., \& Reznakova, M. (2017). Predicting the Bankruptcy of Construction Companies: A CART-Based Model. Engineering Economics, 28(2), 145-154. https://doi.org/10.5755/j01.ee.28.2.16353

Kim, Y. S., \& Park, H. I. (2012). Committee Neural Network for Estimating Preconsolidation Pressure from Piezocone Test Reset. Engineering Computations, 29(8), 842-855. https://doi.org/10.1108/02644401211271618

Korableva, O., \& Kalimullina, O. (2016). Strategic Approach to the Optimization of Organization Based on the BSC SWOT Matrix. Proceedings of the International Conference on Knowledge, 212-215. https://doi.org/10.1109/ICKEA.2016.7803021

Kubanova, J. (2008). Statistické metody pro ekonomickou a technickou praxi. Bratislava: STATIS

Kubenka, M. (2014). The Factors Affecting The Accuracy of Business Failure Prediction Models. Proceedings of European Financial Systems, 364-371.

Kubenka, M., \& Kralova, V. (2013). Z" Score in Assessing the Financial Health in the Construction Sector. E + M Ekonomics and Management, 16(1), 101-112.

Kubenka, M., \& Slavicek, O. (2014). Detection of Cognation between Creditworthy Models and Bankruptcy Models. Proceedings of Managing and Modelling of Financial Risks, 426-433.

Machek, O., \& Spicka, J. (2014). Productivity and Profitability of the Czech Agricultural Sector After the Economic Crisis. WSEAS Transactions on Business and Economics 11, 700-706.

Manasova, Z. (2008). Upadky podniku v Ceske republice a moznosti jejich vcasne predikce. Doctoral thesis. University of Economics Prague.

Ministry of Industry and Trade. (2014). Financial Analysis. Retrieved October 28, 2016, available from internet: https://www.mpo.cz/dokument157262.html

Ministry of Industry and Trade, Methodological Part. Retrieved February 03, 2016, available from internet: http://www. mpo.cz/cz/infa-cznace-metodika. pdf.

Neumaier, I., \& Neumaierova, I. (2010). IN05 Index to Indicate the Crisis. How to Continue after the Crisis. Proceedings of International Scientific Conference, 28-33.

Neumaierova, I. (2005). Index IN05. Proceeding of European Financial Systems, 143-148.

Neumaierova, I., \& Neumaier, I. (2002). The Performance and Market Value of the Company. Praha: Grada 
Ohlson, J. A. (1980). Financial Ratios and the Probabilistic Prediction of Bankruptcy. Journal of Accounting Research, 18(11), 109-131. https://doi.org/10.2307/2490395

Pacakova, V., Pardelova, R., Sodomova, E., \& Soltes, E. (2003). Statistics for Economists. Bratislava: Iura Edition.

Sheng, X., \& Thevenot, M. (2012). A New Measure of Earnings Forecast Uncertainty. Journal of Accounting and Economics, 53(1/2), 21-33. https://doi.org/10.1016/j.jacceco.2011.11.001

Slavicek, O. (2015). Predikční model finančního zdraví pro podniky ve stavebnictví. Proceedings of Financial Management of Firms and Financial Institutions: 10th International Scientific Conference Proceedings. 1166-1173.

Striteska, M. (2012). Key Features of Strategic Performance Management Systems in Manufacturing Companies. Procedia Social and Behavioral Sciences, 58, 1103-1110. https://doi.org/10.1016/j.sbspro.2012.09.1091

Svobodova, L. (2013). Trends in the Number of Bankruptcies in the Czech Republic. Proceedings of Hradec Economic Days. 393-399.

Taffler, R. J. (1984). The Audit Going-concern in Practice. Accounting Magazine, 88, 263-269.

Tamari, M. (1966). Financial Ratios as a Means of Forecasting Bankruptcy. Management International Review, 6(4), 15-21.

Vochozka, M. (2011). Methods of Comprehensive Evaluation of Enterprise. Prague: Grada Publishing

Wilson, R., \& Sharda, R. (1994). Bankruptcy Prediction Using Neural Networks. Decision Support Systems, 11(5), $545-557$. https://doi.org/10.1016/0167-9236(94)90024-8

Zhang, G., \& Hu, M. et al. (1999). Artificial Neural Networks in Bankruptcy Prediction: General framework and cross-validation analysis. European Journal of Operational Research, 116, 16-32. https://doi.org/10.1016/S0377-2217(98)00051-4

Zmijewski, M. E. (1984). Methodological Issues Related to the Estimation of Financial Distress Prediction Models. Journal of Accounting Research, 22, 59-82. https://doi.org/10.2307/2490859

Sunaga, T. (2009). Theory of interval algebra and its application to numerical analysis. Japan Journal on Industrial and Applied Mathematics, 26(2/3), 126-143. https://doi.org/10.1007/BF03186528

The article has been reviewed.

Received in May, 2017; accepted in November, 2018. 